\title{
PMMA denture base material enhancement: a review of fiber, filler, and nanofiller addition
}

\author{
This article was published in the following Dove Press journal: \\ International Journal of Nanomedicine \\ 17 May 2017 \\ Number of times this article has been viewed
}

\author{
Mohammed M Gad' \\ Shaimaa M Fouda ${ }^{1,2}$ \\ Fahad A Al-Harbi' \\ Ritva Näpänkangas ${ }^{2,3}$ \\ Aune Raustia ${ }^{2,3}$ \\ 'Department of Substitutive Dental \\ Sciences, College of Dentistry, \\ University of Dammam, Dammam, \\ Kingdom of Saudi Arabia; ${ }^{2}$ Research \\ Unit of Oral Health Sciences, Faculty \\ of Medicine, University of Oulu, Oulu, \\ Finland; ${ }^{3}$ Medical Research Center, \\ Oulu, Oulu University Hospital and \\ University of Oulu, Oulu, Finland
}

Correspondence: Mohammed M Gad College of Dentistry, Dammam University, PO Box 1982 Dammam 3|44I, Saudi Arabia Email dr.gad@hotmail.com; mmjad@uod.edu.sa

\begin{abstract}
This paper reviews acrylic denture base resin enhancement during the past few decades. Specific attention is given to the effect of fiber, filler, and nanofiller addition on poly(methyl methacrylate) (PMMA) properties. The review is based on scientific reviews, papers, and abstracts, as well as studies concerning the effect of additives, fibers, fillers, and reinforcement materials on PMMA, published between 1974 and 2016. Many studies have reported improvement of PMMA denture base material with the addition of fillers, fibers, nanofiller, and hybrid reinforcement. However, most of the studies were limited to in vitro investigations without bioactivity and clinical implications. Considering the findings of the review, there is no ideal denture base material, but the properties of PMMA could be improved with some modifications, especially with silanized nanoparticle addition and a hybrid reinforcement system.
\end{abstract}

Keywords: denture base, PMMA, reinforcement, nanoparticles, fibers, fillers

\section{Introduction}

Although dental implants are increasingly used in the treatment of edentulous patients, in many cases a conventional complete denture is still the treatment of choice for medical and financial reasons. ${ }^{1}$ An ideal denture base material should have adequate mechanical and physical properties, besides biocompatibility and aesthetics. $^{2}$ Poly(methyl methacrylate) (PMMA) is frequently used to fabricate denture bases due to its various advantages, including low cost, biocompatibility, ease of processing, stability in the oral environment, and acceptable aesthetics. However, it is not considered an ideal material because of its inferior physical and mechanical properties. ${ }^{3}$

Several studies have been conducted with the goal of enhancing the properties of PMMA by using different curing methods and/or incorporating fillers in its composition. ${ }^{2,3}$ Addition of fillers and fibers to PMMA is a commonly used method to improve both its physical and mechanical properties. ${ }^{3}$ This paper reviews different types of fibers and fillers added to PMMA denture base resin and evaluates their effect on the physical and mechanical properties. The review includes data and source information available from scientific papers, reviews, and abstracts published from 1974 to 2016 . The published material was searched in dental literature using general and specialist databases (Google scholar/PubMed database) and the keywords: denture base, PMMA, reinforcement, nanoparticles, fibers, and fillers.

\section{Discussion}

Many additives have been suggested to enhance the properties of denture base resin, such as fibers, fillers, or nanofillers (Table 1). 


\section{Fibers}

Reinforcement of acrylic resin with fibers has been reported to improve the flexural and impact strength as well as the fatigue resistance of the resin. ${ }^{4}$ Several studies have been conducted using different types of fibers, such as nylon, polyethylene, polyamide fiber, and particularly glass fiber, due to their biocompatibility and superior aesthetics and mechanical properties. ${ }^{4,5}$

\section{Glass fiber}

Glass fiber reinforcement has been found to significantly increase the flexural strength, impact strength, toughness, and Vickers hardness of acrylic resin. ${ }^{6-10}$ Also, a significant reduction in deformation of the denture base to less than $1 \%$ deformation was found. ${ }^{6}$ Moreover, a recent study found that the position of glass fiber within the denture base affects its flexural properties. Improvement of flexural strength, toughness, and flexural modulus was obtained from placement of glass fiber close to the surface of the denture base on its tensile stress side. When glass fiber was placed in neutral stress area, only flexural toughness was improved, and when placed in the compressive side, surface flexural modulus was increased. ${ }^{11}$ However, one study indicated that glass fiber impregnation into acrylic resin did not affect its linear dimensional stability. ${ }^{12}$

Preimpregnated and silane [3-(Trimethoxysilyl) propyl methacrylate (TMSPM)]-treated glass fiber also increased the flexural strength ${ }^{13}$ and impact strength of acrylic resin. ${ }^{14,15}$ Silanized glass fiber was found to be biocompatible when added to heat-cured and light-cured resins. ${ }^{6,16}$ Moreover, fiber-reinforced nanopigmented PMMA showed reduced porosity and Candida albicans adherence. ${ }^{6}$

\section{Polyamide fiber}

Polyamide fiber includes both Nylon and Aramid (Kevlar, DuPont, Wilmington, DE, USA) fiber. Aramid fiberreinforced denture base resin was found biocompatible, and additionally its flexural strength and flexural modulus were increased. ${ }^{17}$ However, the hardness of the resin decreased with increasing fiber concentration. Also, its yellow color is considered a drawback. ${ }^{18,19}$ Nylon increased the fracture resistance of PMMA, as it has high resistance to continual stress. Therefore, incorporating nylon fiber in PMMA increased its structural elasticity. ${ }^{20}$

\section{Polyethylene and polypropylene fibers}

Polyethylene fiber significantly increased the impact strength of PMMA, and a further increase was observed with fiber

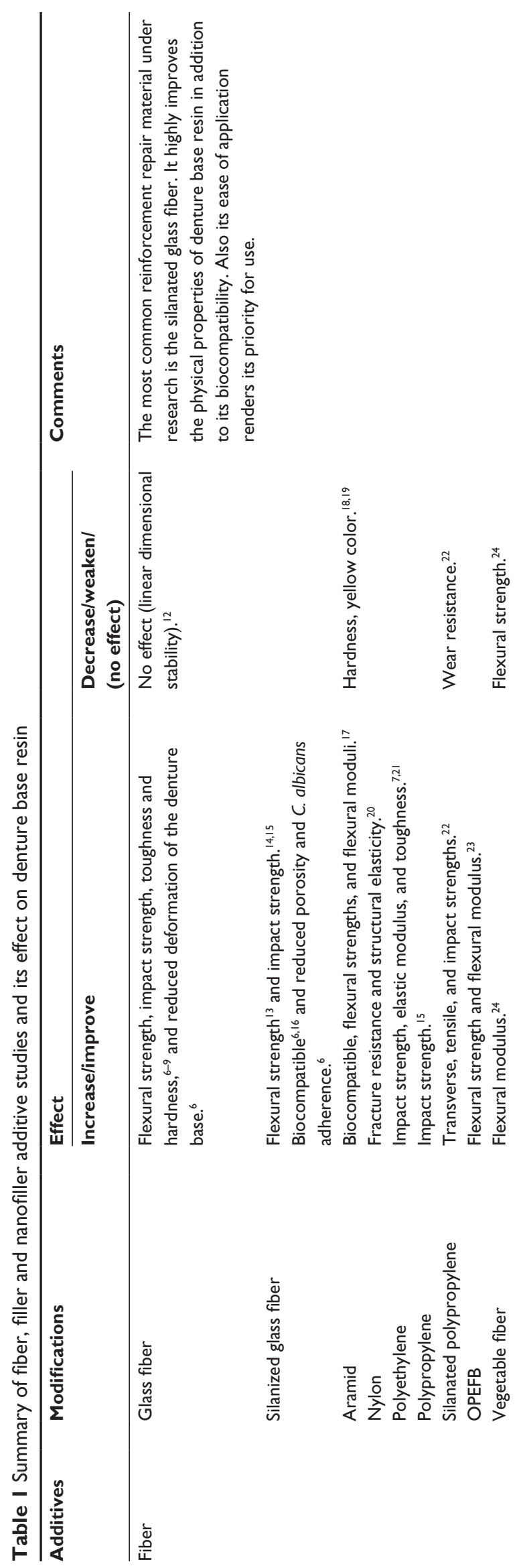



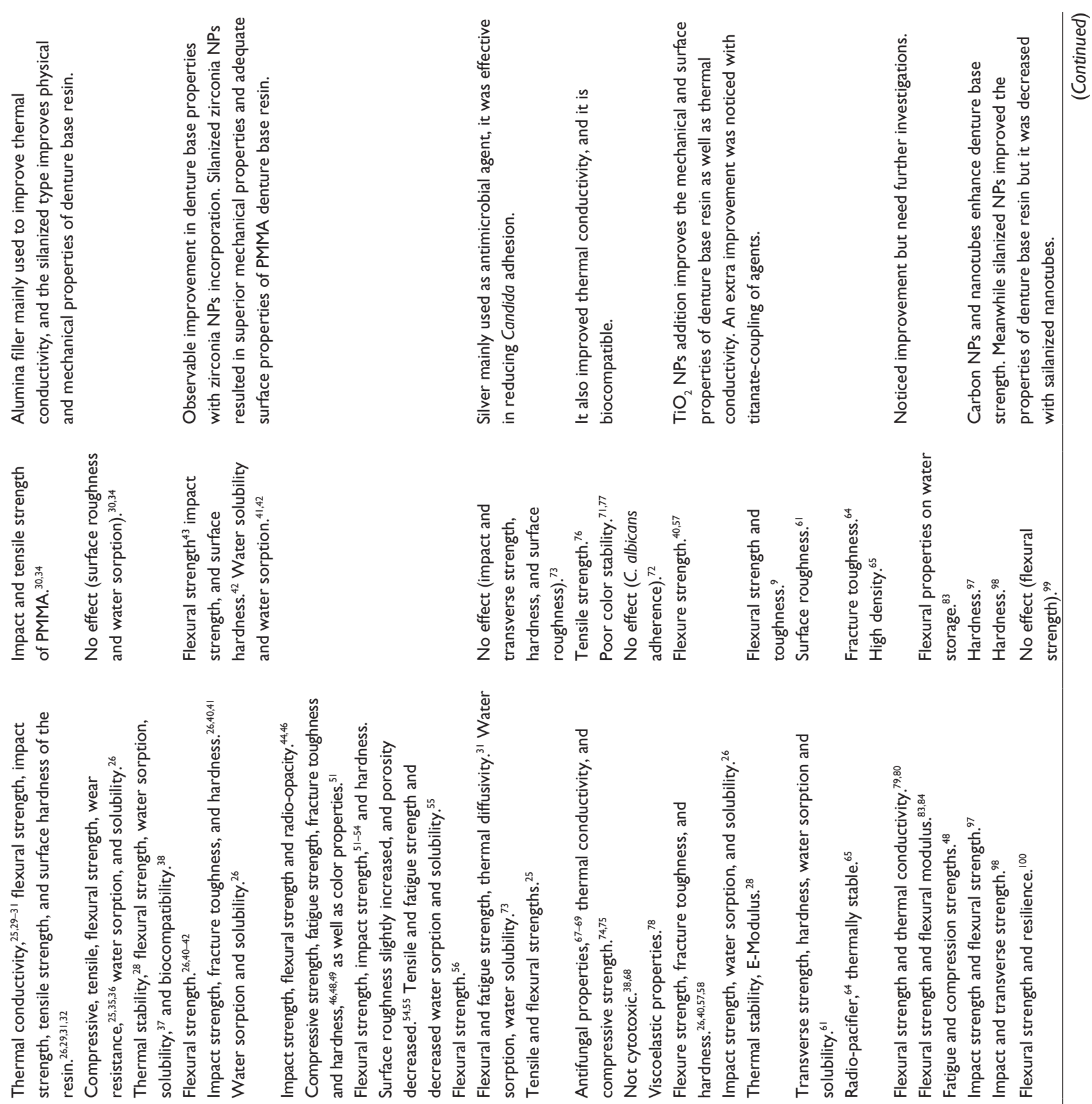

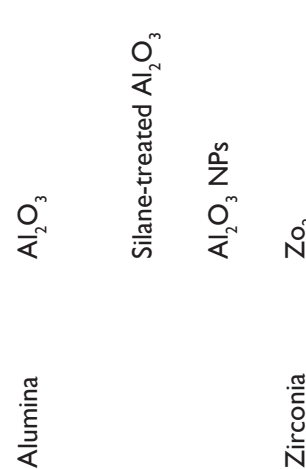

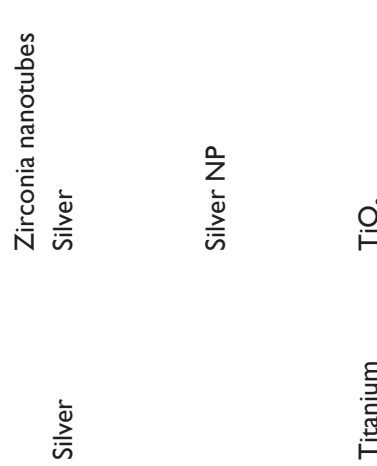

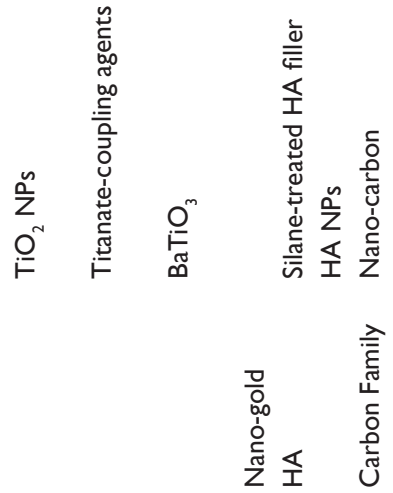


surface treatment. ${ }^{7,21}$ Woven polyethylene fiber reinforcement can significantly increase the elastic modulus and toughness of PMMA. However, the procedures of woven fiber etching, preparing, and positioning were found impractical. ${ }^{21}$ Polypropylene fiber increased the impact strength of PMMA, and surface treatment of the fiber resulted in a further increase in its impact strength. ${ }^{15}$ The highest impact strength was obtained with polypropylene fibers treated with plasma, which can be used to strengthen acrylic resin and reduce fracturing. ${ }^{15}$ A recent study found that incorporating silanized polypropylene fiber in heat-cured PMMA resin significantly improved its transverse, tensile, and impact strengths, but its wear resistance was highly decreased. ${ }^{22}$

\section{Natural fibers}

Natural fibers were suggested to reinforce denture base resins, among which are, oil palm empty fruit bunch (OPEFB) and vegetable fiber (ramie fiber). OPEFB significantly increased the flexural strength and flexural modulus of acrylic resin. ${ }^{23}$ Short ramie fiber also increased the flexural modulus of acrylic resin compared with conventional PMMA, but its flexural strength decreased as a result of weak interfacial bonding. The drawback of this fiber was its presentation in a long form, which requires extra work, ie, cutting and preparation. ${ }^{24}$

\section{Fillers}

Several studies were conducted on using fillers (Table 2) to strengthen denture base resin, and they found significant improvement in its properties. Reinforcement of PMMA with metal oxides improved the physical and mechanical properties of the material, as well as patients' sensation of hot and cold stimuli. Consequently, better food sensation and healthier oral mucosa were expected by adding metal fillers to denture base resin. ${ }^{25-27}$ Recently, the incorporation of nanofillers (Table 2) has been suggested to improve PMMA properties. The high surface area, fine size, and homogenous distribution of nanofillers improved the thermal properties of PMMA and increased its thermal stability compared with pure PMMA. ${ }^{26-28}$ The properties of resin reinforced by nanofillers depend on the size, shape, type, and concentration of the added particles. ${ }^{28}$

\section{Metal oxides} Alumina $\left(\mathrm{Al}_{2} \mathrm{O}_{3}\right)$

Arora et $\mathrm{a}^{29}$ recently reviewed the effect of alumina addition and reported a positive impact on the properties of acrylic resin. Addition of alumina powder to acrylic resin 
Table 2 Classification of reviewed fillers and nanofillers

\begin{tabular}{lll}
\hline Additives & Filler (Size $-\mu \mathrm{m})$ & Nano-filler (Size -nm) \\
\hline Metal oxides & Aluminum oxide $\left(\mathrm{Al}_{2} \mathrm{O}_{3}\right)$ & $\mathrm{Al}_{2} \mathrm{O}_{3}$ \\
& Zirconium oxide $\left(\mathrm{ZrO}_{2}\right)$ & $\mathrm{ZrO}_{2}$ and nanotube \\
Noble metals & Titanium oxide $\left(\mathrm{TiO}_{2}\right)$ & $\mathrm{TiO}_{2}$ \\
& Silver $(\mathrm{Ag})$ & $\begin{array}{l}\mathrm{AgNPs} \\
\text { Gold (Au) }\end{array}$ \\
& & Platinum (Pt) \\
& & Palladium (Pd) \\
Mineral & $\mathrm{HA}$ & $\mathrm{HA}$ \\
& Silicon dioxide $\left(\mathrm{SiO}_{2}\right)$ & $\mathrm{SiO}$ \\
& Mica & \\
& & Nanoclay \\
& & $\mathrm{HNT}$ \\
Carbon & & Nano-carbon \\
family & & NDs \\
\hline
\end{tabular}

Abbreviations: HA, hydroxyapatite; HNT, Halloysite nanotube; ND, nanodiamond; NP, nanoparticle.

improved its thermal conductivity and, accordingly, patient satisfaction was expected to increase..$^{25,30-33}$ In addition, reinforcing PMMA with aluminum increased the flexural strength, impact strength, tensile strength, compressive strength, and surface hardness of the resin. ${ }^{26,30,32,34}$ Warpage also decreased significantly after addition of aluminum to PMMA. On the other hand, some studies found that adding aluminum decreases both the impact and tensile strength of PMMA. ${ }^{31,35}$ The resin was weakened due to stress concentration around the embedded metal and its poor adhesion to the polymer.

However, several methods such as sandblasting, silanization, and metal adhesive resins were suggested to improve the bond between the acrylic resin and metal surface. ${ }^{27}$ Treating aluminum oxide particles with a coupling agent increased the flexural properties of acrylic resin. ${ }^{36,37}$ Also, silane-treated aluminum particles significantly increased the compressive, tensile, and flexural strength and the wear resistance of reinforced denture base resin. ${ }^{25,37}$

Surface roughness and water sorption were not significantly changed with aluminum-reinforced denture resin. ${ }^{31,35}$ However, one study found a significant decrease in water sorption and solubility after addition of $\mathrm{Al}_{2} \mathrm{O}_{3},{ }^{26}$ and an increase in water sorption was found by another study. ${ }^{31}$

Safi ${ }^{28}$ concluded that adding $\mathrm{Al}_{2} \mathrm{O}_{3}$ nanoparticles (NPs) to PMMA increases its thermal stability compared with pure PMMA. Addition of silanized $\mathrm{Al}_{2} \mathrm{O}_{3}$ NPs to acrylic resin improved the thermal properties (decreased the thermal expansion coefficient and contraction) and flexural strength of acrylic resin, and at the same time this addition decreased water sorption and solubility. ${ }^{38}$ A recent study reported that alumina NPs have a good level of biocompatibility when added to microwave-treated and untreated PMMA powder. ${ }^{39}$ The disadvantage of aluminum-reinforced PMMA is discoloration of the resin, which limits its use to areas where it is not visible. ${ }^{38}$ Although the addition of $\mathrm{Al}_{2} \mathrm{O}_{3}$ to PMMA significantly increased thermal conductivity, the flexural strength values of PMMA were not significantly changed. ${ }^{33}$

\section{Zirconia $\left(\mathrm{ZrO}_{2}\right)$}

Several studies found that incorporating zirconia $\left(\mathrm{ZrO}_{2}\right)$ fillers in PMMA significantly increased its flexural strength. ${ }^{26-42}$ However, a slight decrease in flexural strength was also reported; it may result from clustering of the particles within the resin, which weakened the material. ${ }^{43}$ In addition, the impact strength, fracture toughness, and hardness of PMMA were increased significantly by incorporating $\mathrm{ZrO}_{2}{ }^{26,40} \mathrm{On}$ the other hand, one study found an insignificant increase in the impact strength and surface hardness of zirconia-reinforced resin compared with unreinforced PMMA. ${ }^{41} \mathrm{~A}$ decrease in both impact strength and surface hardness was also reported. ${ }^{42}$ Also, addition of $\mathrm{ZrO}_{2}$ significantly increased the thermal conductivity of PMMA. ${ }^{33}$ Different results were obtained regarding the effect of $\mathrm{ZrO}_{2}$ on the water sorption and solubility of PMMA. It was found that adding $\mathrm{ZrO}_{2}$ significantly decreased the water sorption and solubility of PMMA, ${ }^{26}$ while an insignificant difference in water solubility and an increase in water sorption within the limit of ADA specifications were also reported. ${ }^{41,42}$

Adding zirconia NPs was suggested to improve the mechanical properties of PMMA. ${ }^{44,45}$ Incorporating zirconia NPs in PMMA increased its impact strength, flexural strength, ${ }^{44,46,47}$ compressive strength, fatigue strength, as well as its fracture toughness and hardness. ${ }^{46,48,49}$ In addition, it may have an antifungal effect and may play a preventive role in patients susceptible to fungal infections. ${ }^{50}$ On the other hand, one study found an insignificant increase in the hardness of nano- $\mathrm{ZrO}_{2} / \mathrm{PMMA}$, and its surface roughness was not significantly changed ${ }^{44}$ Safi et al,,${ }^{51}$ studied the effect of zirconia NP addition on the color properties of PMMA and did not find any noticeable color changes.

Poor wettability between fillers and the resin matrix reduced improvement of the physical and mechanical properties of PMMA. Therefore, a silane coupling agent was used to improve the bond strength between zirconia NPs and PMMA. It resulted in increased flexural strength and impact strength of acrylic resin, but its tensile strength was not improved. ${ }^{51-54}$ However, one study found that silanized zirconia NPs improved the tensile strength and 
fatigue strength of PMMA. ${ }^{55}$ Also hardness increased significantly and surface roughness increased slightly when silanized zirconia NPs were incorporated in acrylic resin, while apparent porosity, ${ }^{54,55}$ water sorption, and solubility decreased. ${ }^{55}$

In addition, zirconia nanotubes showed a better reinforcing effect than zirconia NPs. In contrast to zirconia NPs, surface treatment would lower the reinforcing effect of zirconia nanotubes. It was found that flexural strength was maximized when $2 \mathrm{wt} \%$ untreated zirconia nanotubes were added to PMMA. ${ }^{56}$

\section{Titanium $\left(\mathrm{TiO}_{2}\right)$}

Several studies have investigated the effect of adding titanium dioxide $\left(\mathrm{TiO}_{2}\right)$ on the properties of PMMA. It was found that adding $\mathrm{TiO}_{2}$ particles could improve the flexure strength, fracture toughness, hardness of PMMA, ${ }^{26,40,57,58}$ as well as thermal conductivity. ${ }^{33}$ In addition, a significant increase in impact strength ${ }^{59}$ and a significant decrease in water sorption and solubility were found upon addition of $\mathrm{TiO}_{2}$ to PMMA. ${ }^{26}$ Conversely, some studies found that $\mathrm{TiO}_{2}$ did not improve the flexure strength of PMMA, which could be attributed to clustering of the particles within the resin, causing its weakness. ${ }^{40,57}$

$\mathrm{Safi}^{28}$ found that modifying PMMA with $\mathrm{TiO}_{2}$ NPs has an effect on its thermal (decrease in the thermal expansion coefficient and contraction) and mechanical (decreased E-Modulus) stability, while a reduction in flexural strength and toughness was reported. ${ }^{9,59}$ Adhesion between the resin matrix and filler particles is very important in order to enhance the composite's properties. Accordingly, a titanium coupling agent could be useful for improving the properties of titanium-reinforced PMMA. ${ }^{60}$ Incorporation of silanized $\mathrm{TiO}_{2}$ NPs in PMMA improved the impact strength, transverse strength, and surface hardness of the resin and decreased its water sorption and solubility. Moreover, surface roughness increased with the addition of $3 \mathrm{wt} \%$ of silanized $\mathrm{TiO}_{2}$ NPs to acrylic resin. ${ }^{61}$ Addition of apatite-coated titanium dioxide and fluoridated apatite-coated titanium dioxide after treatment with ultraviolet A irradiation of PMMA inhibited Candida adhesion due to their antifungal effect, and their use could be beneficial in obtaining appropriate denture hygiene. ${ }^{62,63}$ Addition of barium titanate $\left(\mathrm{BaTiO}_{3}\right)$ as a radiopacifier to PMMA showed a slight decrease in fracture toughness properties. ${ }^{64}$ It was found that $\mathrm{PMMA} / \mathrm{BaTiO}_{3}$ composite is thermally stable, but its increased density affects denture retention. ${ }^{59,65}$

\section{Noble metals}

\section{Silver $(\mathrm{Ag})$}

Several studies found that addition of silver NPs (AgNPs) to denture base acrylic resin displayed antifungal properties, ${ }^{66-69}$ especially at high concentrations, ${ }^{70}$ and acted like a latent antifungal material with low-releasing $\mathrm{Ag}^{+} .{ }^{71}$ On the contrary, Wady et $\mathrm{al}^{72}$ found that incorporating silver NPs in PMMA did not affect the adhesion of C. albicans and biofilm accumulation.

Silver has an antimicrobial effect; its addition to PMMA could reduce microbial adhesion and colonization. ${ }^{66,67}$ Therefore, its use could be beneficial for immune-compromised and geriatric patients. ${ }^{67}$ In addition, silver-reinforced PMMA resin has increased flexural and fatigue strength and improved thermal conductivity. ${ }^{32,33}$ However, it was found that incorporating $0.5 \%$ of antimicrobial silver-zinc zeolite in heat-cured acrylic resin did not affect its impact and transverse strength, the surface hardness, and the surface roughness of the resin. It did not change its color, but a significant decrease in water sorption and an increase in water solubility were found in the acrylic resin. ${ }^{73}$ On the other hand, it was suggested that, depending on its percentage, adding silver may negatively affect the mechanical properties of denture base resin. ${ }^{66}$ Incorporating silane-treated silver particles significantly increased the compressive strength of PMMA. Also, addition of $10 \mathrm{wt} \%$ and $20 \mathrm{wt} \%$ silane-treated silver fillers enhanced the tensile and flexural strength of PMMA..$^{25}$ Addition of silver powder to PMMA significantly increased thermal conductivity; the flexural strength values of PMMA were not significantly changed..$^{33}$

The physical and mechanical properties of PMMA were enhanced by the addition of silver NPs, including improvement of thermal conductivity and compressive strength..$^{74,75}$ Therefore, it is recommended to be used in the palatal area of maxillary acrylic resin dentures. ${ }^{74}$ Also, it was found that PMMA-silver NPs are not cytotoxic. ${ }^{39,68}$ However, tensile strength did not change significantly after incorporating $0.2 \%$ of AgNPs in comparison with unmodified PMMA, but it decreased significantly after incorporation of $2 \%{ }^{76}$ In addition, poor color stability of PMMA-AgNPs was reported. ${ }^{71,77}$ Incorporating AgNPs in acrylic denture base material can improve its viscoelastic properties. ${ }^{78}$

\section{Nano-gold $(\mathrm{Au})$, platinum $(\mathrm{Pt})$, palladium $(\mathrm{Pd})$}

Nano-gold $(\mathrm{Au})$ and platinum $(\mathrm{Pt}) \mathrm{NPs}$ recently were suggested to improve the properties of PMMA denture base. The studies available on the effect of adding nano-gold to PMMA 
are still limited at the present time. It has been observed that incorporating gold NPs considerably improved the flexural strength and thermal conductivity to almost double the value of pure PMMA, which could lead to more patient satisfaction. ${ }^{79,80}$ Addition of Pt NPs could improve mechanical properties of PMMA and provide antimicrobial effect. ${ }^{81}$ It was found that platinum significantly increased the bending deflection of PMMA and that palladium improved the bending strength when compared to silver and gold, which showed the lowest value of bending strength. Addition of gold and palladium improved Vickers hardness of PMMA and was decreased with the addition of platinum. ${ }^{82}$

\section{Minerals}

Hydroxyapatite fillers

Hydroxyapatite fillers (HA) added to PMMA resulted in superior mechanical properties. It increased the flexural strength as well as the flexural modulus of PMMA. ${ }^{83}$ The interfacial interaction between HA filler and the PMMA matrix is enhanced by treatment with $\gamma$-MPS. ${ }^{83,84}$ But a reduction in the flexural properties on water immersion was attributed to water's plasticizing effect, which weakens the bonding between the HA filler and the PMMA matrix. ${ }^{83}$ The addition of HA NPs also increased both the fatigue and compression strength of PMMA resin in comparison with pure PMMA, ${ }^{48}$ in addition to significant increase in thermal conductivity. ${ }^{33}$

\section{Silicon dioxide $\left(\mathrm{SiO}_{2}\right)$}

The mechanical and thermal properties of PMMA were enhanced by the incorporation of silicon dioxide $\left(\mathrm{SiO}_{2}\right) \mathrm{NPs} .^{28}$ Improvement of both the impact and transverse strength of PMMA was achieved by the addition of $\mathrm{SiO}_{2}$ NPs. Surface hardness also increased with a higher $\mathrm{SiO}_{2} \mathrm{NP}$ concentration. ${ }^{85}$ However, improved hardness and fracture toughness were found with a low concentration of $\mathrm{SiO}_{2} \mathrm{NPs}$. Increasing its content resulted in agglomeration and crack propagation, which reduces both hardness and fracture toughness ${ }^{86}$ Addition of surface-treated silica improved the flexural strength of PMMA but did not affect hardness ${ }^{87}$ On the other hand, a recent study found that silica NPs adversely affect the flexural strength of PMMA. ${ }^{88}$

\section{Silica-based filler}

Reinforcement of acrylic resin with glass flakes enhanced its fracture toughness, and the use of silane coupling resulted in further improvement of the resin's properties. ${ }^{40}$ Micas are a group of lamellar silicate minerals, which have been suggested to improve resin's properties. These lamellar silicate minerals are characterized by their high aspect ratio, and they improved the mechanical, thermal, as well as dimensional properties of PMMA. ${ }^{89}$ The hardness of acrylic resin increased with the incorporation of mica, but its flexural strength was reduced because of mica's weak bond with the acrylic resin..$^{90}$ It was also found that addition of fluoride glass fillers to PMMA decreased microbial adhesion, although it slightly increased surface roughness of the denture base resin..$^{91-93}$ Nanoclay is another material which is used to improve the properties of composite and acrylic polymers. The addition of Nanoclay particles to PMMA improved its thermal conductivity, while it had a negative effect on the flexural strength. ${ }^{94}$ Placing silicon carbide filler powders in the palatal region of dentures can improve the thermal conductivity of PMMA without reducing strength or increasing weight. ${ }^{33}$ The halloysite nanotube is a silica-based naturally occurring mineral which introduced by Abdallah ${ }^{95}$ in 2016 to improve the properties of PMMA. Halloysite nanotube increased hardness of PMMA when added in small percentages, while the flexural strength and Young's modulus did not show a significant increase.

\section{Carbon family fillers}

Carbon fillers are not commonly used to reinforce PMMA because of biological problems, poor aesthetics, as well as difficulty in handling and polishing. ${ }^{18}$ But nowadays, nanocarbon is one of the main branches of nanotechnology. ${ }^{96}$

\section{Nano-carbon}

Addition of $1 \%$ of carbon nanotubes to PMMA was found to significantly increase the impact strength and flexural strength of the resin, but its hardness was decreased. ${ }^{97}$ It was also found that adding $1.5 \%$ of single-walled carbon nanotubes significantly increased the impact and transverse strength of PMMA, but significantly decreased its surface hardness..$^{98}$ Conversely, one study reported an insignificant effect of adding single-walled carbon nanotubes on the flexural strength of PMMA. ${ }^{99}$ Addition of $0.5 \%$ and $1 \%$ of multiple-wall carbon nanotubes (MWCNTs) improved the flexural strength and resilience of PMMA, while its fatigue resistance was decreased with higher concentrations of multiple-wall carbon nanotubes. ${ }^{100}$

\section{Nano-diamonds}

The outstanding properties of nano-diamonds (NDs), ie, high hardness and thermal conductivity, suggested its use to 
improve the mechanical properties of PMMA. ${ }^{101,102}$ NDs significantly increased the impact strength of PMMA, and also improvement in fracture toughness was found, but only at the lowest concentration of NDs. ${ }^{103}$ Moreover, heat-treated NDs increased the scratch resistance of PMMA. ${ }^{104}$ Some drawbacks were attributed mainly to agglomeration of the NPs, which could act as points of stress concentration. ${ }^{105}$

\section{Hybrid reinforcement}

Reinforcement of PMMA by more than one type of fiber was first suggested by Vallittu in 1997. ${ }^{106}$ As listed in Table 3, the combination may be between different fibers, ${ }^{7}$ different metal oxides and ceramics, ${ }^{107-111}$ and fibers with metal oxides, ${ }^{112,113}$ or ceramic materials. ${ }^{48,114-116}$

Hybrid fiber reinforcement significantly increased the flexural strength and toughness of reinforced acrylic resin. ${ }^{14}$ Similar results were also obtained by incorporating metal oxides and ceramics, especially NPs, in PMMA. ${ }^{116}$ In addition to improving surface roughness, ${ }^{109}$ tensile strength, flexural modulus, ${ }^{114}$ hardness, and thermal conductivity, ${ }^{116}$ and radiopacity ${ }^{111}$ as well as reducing shrinkage, ${ }^{107,110}$ it has antibacterial properties without showing cytotoxicity. ${ }^{108}$

A combination of fibers and other fillers also increased impact strength, hardness, ${ }^{112}$ surface roughness, and thermal conductivity, ${ }^{113}$ as well as compressive and fatigue strengths. ${ }^{71}$

\section{Summary and clinical implications}

For years, acrylic dental prosthesis has been used for treatment of edentulous patients to improve their quality of life. It has several advantages including, considerable price, aesthetics, and ease of manipulation. However, it is susceptible to fracture

Table 3 Different hybrid reinforcement materials

\begin{tabular}{|c|c|}
\hline Hybrid type & Hybrid materials \\
\hline Fibers & Glass fiber + polyethylene fibers ${ }^{7}$ \\
\hline Fillers & $\begin{array}{l}-\mathrm{Al}_{2} \mathrm{O}_{3}+\mathrm{ZrO}_{2}{ }^{114,109} \\
-\mathrm{ABWs}+\mathrm{Al}_{2} \mathrm{O}_{3}^{115,108} \\
-\mathrm{ZrO}_{2}-\mathrm{TiO}_{2}{ }^{116}\end{array}$ \\
\hline Fibers + fillers & $\begin{array}{l}\text { - Polyester fiber reinforced } \mathrm{PMMA}+ \\
\left.\quad \text { (clay, glass powder, } \mathrm{SiO}_{2} \text {, or } \mathrm{ZrO}_{2}\right)^{112} \\
-\mathrm{Al}_{2} \mathrm{O}_{3}+\text { plasma-treated polypropylene fiber } \\
\text { nHA particles, micro-zirconia, glass fiber, and } \\
\text { Kevlar fiber } \\
\text { (PMMA-nHA and glass fiber), } \\
\text { (PMMA-ZrO and glass fiber) } \\
\text { (PMMA-nHA and Kevlar fiber), } \\
\text { (PMMA-ZrO and Kevlar fiber) }{ }^{48}\end{array}$ \\
\hline
\end{tabular}

Abbreviations: $A B W$, aluminum borate whisker; $\mathrm{nHA}$, nano-hydroxyapatite; PMMA, poly(methyl methacrylate). or deformation due to its inferior mechanical and physical properties. Several attempts have been implemented to improve the properties of PMMA including addition of reinforcing material as fibers, fillers hybrid reinforcement, and, recently, NPs. However, the most effective reinforcement is not apparent, and clinicians are confused about designing such reinforcement. Moreover, some authors reported that reinforcement involved the addition of a foreign material to prostheses, and may thus be a risk factor for fracture development, rather than fracture prevention. Currently, reinforcement has two important purposes on a prosthesis. The initial purpose is to improve the strength and prevent fracture, and of the previous studies were conducted with a focus on this purpose. The second purpose is to improve the stiffness and prevent residual ridge resorption and overloading to residual teeth or structures. To summarize this review, reinforcements within denture base acrylic resins undoubtedly had some efficacy in improving the physical and mechanical properties, but the levels varied by material, form, concentrations, surface treatment, and position of the reinforcement. Considering these results, clinicians had better placed some kind of reinforcement in all removable dental prostheses to prevent prosthetic and other complications. However, most of the previous studies were carried out in terms of improving the strength, rather than the rigidity, and studies aimed at improving rigidity remained insufficient even in experimental model and specimen studies. Furthermore, clinical studies about the effect of reinforcement on both prostheses and patients were very few, and in particular, there were no randomized long-term clinical studies comparing prostheses with and without reinforcement. Therefore, further studies focusing on the rigidity of prostheses with reinforcement and its effect on underlying structures such as the residual ridge or implant as well as longitudinal clinical studies, are necessary to ensure the effect of reinforcement within dental prostheses. In the future, the possibilities to use a high strength biomaterial with low modulus should also be taken into consideration.

\section{Conclusion}

Based on this comprehensive review it can be concluded that:

- Glass fiber reinforcement significantly increases the mechanical properties of PMMA. Natural fibers (OPEFB) and vegetable fiber can be used, but further investigations are needed.

- Obvious enhancement in the properties of denture base resin material properties was found with the addition of 
NPs and nanotubes, depending on the application and manipulation.

- Silane coupling agents play a central role in improving bonding between fillers and the resin matrix, and they subsequently improved the resin's properties.

- The newest reinforcement system is a hybrid one. Hybrid fiber, hybrid fillers, or hybrid fiber and filler may considerably enhance the properties of PMMA.

- Multiple studies were conducted in vitro, so further studies in vivo are needed, as well as clinical studies.

\section{Acknowledgment}

Authors would like to deeply thank Prof Neveen Ayad for her valuable advice in the preparation of this review proposal.

\section{Disclosure}

The authors report no conflicts of interest in this work.

\section{References}

1. Carlsson GE, Omar R. The future of complete dentures in oral rehabilitation. A critical review. J Oral Rehabil. 2010;37:143-156.

2. Meng TR, Latta MA. Physical properties of four acrylic denture base resins. J Contemp Dent Pract. 2005;6:93-100.

3. Alla R, Raghavendra KN, Vyas R, Konakanchi A. Conventional and contemporary polymers for the fabrication of denture prosthesis: part I - overview, composition and properties. Int J Appl Dent Sci. 2015; 1:82-89.

4. Alla R, Sajjan S, Alluri V, Ginjupalli K, Padhya NU. Influence of fiber reinforcement on the properties of denture base resins. J Biomat NanoBiotechnol. 2013;4:91-97.

5. Tacir IH, Kama JD, Zortuk M, Eskimez S. Flexural properties of glass fiber reinforced acrylic resin polymers. Aust Dent J. 2006;51:52-56.

6. Moreno MV, Acosta-Torres LS, Barcel O-Santana FH, Vanegas-Lanc RD, Plata-Rodríguez ME, Casta VM. Fiber-reinforced nano-pigmented poly (methyl methacrylate) as improved denture base. J Appl Polym Sci. 2012;126:289-296.

7. Sang-Hui YU, Yoon LE, Seunghan OH, Hye-Won CH, Yutaka OD, Ji-Myung BA. Reinforcing effects of different fibers on denture base resin based on the fiber type, concentration, and combination. Dent Mater J. 2012;3:1039-1046.

8. Farina AP, Cecchin D, Soares RG, et al. Evaluation of vickers hardness of different types of acrylic denture base resins with and without glass fiber reinforcement. Gerodontol. 2012;29:155-160.

9. Hamouda IM, Beyari MM. Addition of glass fibers and titanium dioxide nanoparticles to the acrylic resin denture base material: comparative study with the conventional and high impact types. Oral Health Dent Manag. 2014;13:107-112.

10. Singh K, Sharma SK, Negi P, Kumar M, Rajpurohit D, Khobre P. Comparative evaluation of flexural strength of heat polymerized denture base resins after reinforcement with glass fibers and nylon fibers: An in vitro Study. Adv Hum Biol. 2016;6:91-94.

11. Agha $\mathrm{H}$, Flinton R, Vaidyanathan T. Optimization of fracture resistance and stiffness of heat-polymerized high impact acrylic resin with localized e-glass fiber reinforcement at different stress points. J Prosthodont. 2016;25(8):647-655.

12. Dalkiz M, Arslan D, Tuncdemir AR, Bilgin MS, Aykul H. Effect of different palatal vault shapes on the dimensional stability of glass fiber reinforced heat-polymerized acrylic resin denture base material. Eur J Dent. 2012;6:70-78.
13. Fonseca RB, Favarão IN, Kasuya VB, Abrão M, Da Luz N FM, Naves LZ. Influence of glass fiber wt $\%$ and silanization on mechanical flexural strength of reinforced acrylics. J Mat Sci Chem Eng. 2014;2:11-15.

14. Hari Prasad A, Kalavathy, Mohammed HS. Effect of glass fiber and silane treated glass fiber reinforcement on impact strength of maxillary complete denture. Ann Essen Dent. 2011;4:7-12.

15. Mowade TK, Dange SP, Thakre MB, Kamble VD. Effect of fiber reinforcement on impact strength of heat polymerized polymethylmethacrylate denture base resin: in vitro study and SEM analysis. $J A d v$ Prosthodont. 2012;4:30-36.

16. Jassim RK, Radhi AA. Evaluation the biological effect of two types of denture base materials reinforced with silanated glass fiber. $J$ Bagh Coll Dent. 2011;23:26-30.

17. Yu SH, Ahn DH, Park JS, et al. Comparison of denture base resin reinforced with polyaromatic polyamide fibers of different orientations. Dental Mater J. 2013;32:332-340.

18. Jagger DC, Harrison A, Jandt KD. The reinforcement of dentures. J Oral Rehab. 1999;26:185-194.

19. Chen SY, Liang WM, Yen PS. Reinforcement of acrylic denture base resin by incorporation of various fibers. J Biomed Mater Res. 2001;58: 203-208.

20. Soygun K, Bolayir G, Boztug A. Mechanical and thermal properties of polyamide versus reinforced PMMA denture base materials. $J A d v$ Prosthodont. 2013;5:153-160.

21. Uzun G, Hersek N, Tinçer T. Effect of five woven fiber reinforcements on the impact and transverse strength of a denture base resin. J Prosthet Dent. 1999;81:616-620.

22. Ismaeel IJ, Alalwan HA, Mustafa MJ. The effect of the addition of silanated polypropylene fiber to polymethylmethacrylate denture base material on some of its mechanical properties. J Bagh Coll Dent. 2015; 27:40-47.

23. John J, Ann Mani S, Palaniswamy K, Ramanathan A, Razak AA. Flexural properties of poly (Methyl Methacrylate) resin reinforced with oil palm empty fruit bunch fibers: a preliminary finding. J Prosthodont. 2015; 24:233-238.

24. Xu J, Li Y, Yu T, Cong L. Reinforcement of denture base resin with short vegetable fiber. Dent Mater. 2013;29:1273-1279.

25. Yadav P, Mittal R, Sood VK, Garg R. Effect of incorporation of silanetreated silver and aluminum microparticles on strength and thermal conductivity of PMMA. J Prosthodont. 2012;21:546-551.

26. Asar NV, Albayrak H, Korkmaz T, Turkyilmaz I. Influence of various metal oxides on mechanical and physical properties of heat-cured polymethylmethacrylate denture base resins. J Adv Prosthodont. 2013;5: 241-247.

27. Sehajpal SB. Effect of metal fillers on some physical properties of acrylic resin. J Prosthet Dent. 1989;61:746-751.

28. Safi IN. Evaluation the effect of nano-fillers $\left(\mathrm{TiO}_{2}, \mathrm{AL}_{2} \mathrm{O}_{3}, \mathrm{SiO}_{2}\right)$ addition on glass transition temperature, E-Moudulus and coefficient of thermal expansion of acrylic denture base material. J Bagh Coll Dent. 2014; 26:37-41.

29. Arora P, Singh SP, Arora V. Effect of alumina addition on properties of polymethylmethacrylate - a comprehensive review. Int J Biotech Trends Technol. 2015;9:1-7.

30. Ellakwa AE, Morsy MA, El-Sheikh AM. Effect of aluminum oxide addition on the flexural strength and thermal diffusivity of heat-polymerized acrylic resin. J Prosthodont. 2008;17:439-444.

31. Abdulhamed AN, Mohammed AM. Evaluation of thermal conductivity of alumina reinforced heat cure acrylic resin and some other properties. J Bagh Coll Dent. 2010;22:1-7.

32. Arora N, Jain V, Chawla A, Mathur VP. Effect of addition of sapphire (Aluminum oxide) or silver fillers on the flexural strength, thermal diffusivity and water sorption of heat-polymerized acrylic resins. Int $J$ Prosthodont Restorat Dent. 2011;1:21-27.

33. Kul E, Aladağ Lİ, Yeşildal R. Evaluation of thermal conductivity and flexural strength properties of poly (methyl methacrylate denture) base material reinforced with different fillers. J Prosthet Dent. 2016; 116:803-810. 
34. Zhang X, Zhang X, Zhu B, Lin K, Chang J. Mechanical and thermal properties of denture PMMA reinforced with silanized aluminum borate whiskers. Dent Mater J. 2012;31:903-908.

35. Vojdani M, Bagheri R, Khaledi AR. Effects of aluminum oxide addition on the flexural strength, surface hardness, and roughness of heat-polymerized acrylic resin. J Dent Sci. 2012;7:238-244.

36. Yadav NS, Elkawash H. Flexural strength of denture base resin reinforced with aluminum oxide and processed by different processing techniques. J Advan Dent Res. 2011;2:33-36.

37. Chaijareenont P, Takahashi H, Nishiyama N, Arksornnukit M. Effect of different amounts of 3-methacryloxypropyltrimethoxy silane on the flexural properties and wear resistance of alumina reinforced PMMA. Dent Mater J. 2012;31:623-628.

38. Jasim BS, Ismail IJ. The effect of silanized alumina nano-fillers addition on some physical and mechanical properties of heat cured polymethylmethacrylate denture base material. J Bagh Coll Dent. 2014;26: $18-23$.

39. Abdulkareem MM, Hatim NA. Evaluation the biological effect of adding Aluminum Oxide, Silver nanoparticles into microwave treated PMMA powder. Int J Enhanc Res Sci Technol Eng. 2015;4:172-178.

40. Franklin P, Wood DJ, Bubb NL. Reinforcement of poly (methyl methacrylate) denture base with glass flake. Dent Mater. 2005;21:365-370.

41. Ayad NM, Badawi MF, Fatah AA. Effect of reinforcement of highimpact acrylic resin with zirconia on some physical and mechanical properties. Rev Clín Pesq Odontol. 2008;4:145-151.

42. Asopa V, Suresh S, Khandelwal M, Sharma V, Asopa SS, Kairal LS. A comparative evaluation of properties of zirconia reinforced high impact acrylic resin with that of high impact acrylic resin. Saudi J Dent Res. 2015;6:146-151.

43. Al-Rais RY, Al-Nakkash WA, Al-Bakri AK. Filler reinforced acrylic denture base material. Part 2-Effect of water sorption on dimensional changes and transverse strength. J Baghdad Coll Dent. 2005;17: 6-10.

44. Safi IN, Moudhaffar M. Evaluation the effect of modified nano fillers addition on some properties of heat cured acrylic denture base material. J Bagh Coll Dent. 2011;23:23-29.

45. Gad MM, Rahoma A, Al-Thobity AM, ArRejaie AS. Influence of incorporation of $\mathrm{ZrO} 2$ nanoparticles on the repair strength of polymethyl methacrylate denture bases. Int J Nanomed. 2016;11:5633-5643.

46. Zhang XJ, Zhang XY, Zhu BS, Qian C. Effect of nano ZrO2 on flexural strength and surface hardness of polymethylmethacrylate. Shanghai Kou Qiang Yi Xue. 2011;20:358-363.

47. Gad M, ArRejaie AS, Abdel-Halim MS, Rahoma A. The reinforcement effect of nano-zirconia on the transverse strength of repaired acrylic denture base. Int J Dent. 2016;2016:7094056.

48. Salih SI, Oleiwi JK, Hamad QA. Investigation of fatigue and compression strength for the PMMA reinforced by different system for denture applications. Int J Biomed Mat Res. 2015;3:5-13.

49. Ahmed MA, Ebrahim MI. Effect of zirconium oxide nano-fillers addition on the flexural strength, fracture toughness, and hardness of heat-polymerized acrylic resin. World J Nano Sci Eng. 2014;4: $50-57$.

50. Cierech M, Kolenda A, Grudniak AM, et al. Significance of polymethylmethacrylate (PMMA) modification by zinc oxide nanoparticles for fungal biofilm formation. Int J Pharm. 2016;510(1):323-335.

51. Safi IN, Hassanen KA, Ali NA. Assessment of zirconium oxide nanofillers incorporation and silanation on impact, tensile strength and color alteration of heat polymerized acrylic resin. J Bagh Coll Dent. 2012; 24:36-42.

52. Bian YM, Zhang XY, Zhu BS, Yu WQ, Ruan DP, Min M. Influence of different amount of silane coupling agent on the flexural strength of PMMA/nanometer $\mathrm{ZrO}_{2}$ composites. Shanghai Kou Qiang Yi Xue. 2007; 16:319-323

53. Zhang XY, Wu WL, Bian YM, Zhu BS, Yu WQ. The effect of different dispersive methods on flexural strength nano- $\mathrm{ZrO}_{2}$ reinforced denture polymethylmethacrylate. Shanghai Kou Qiang Yi Xue. 2009;18: 313-316.
54. Hameed HK, Abdul Rahman H. The effect of addition nano particle $\mathrm{ZrO}_{2}$ on some properties of autoclave processed heat cures acrylic denture base material. J Bagh Coll Dent. 2015;27:32-39.

55. Mohammed D, Mudhaffar M. Effect of modified zirconium oxide nano-fillers addition on some properties of heat cure acrylic denture base material. J Bagh Coll Dent. 2012;24:1-7.

56. Yu Wei, Wang X, Tang Q, Guo M, Zhao J. Reinforcement of denture base PMMA with $\mathrm{ZrO}_{2}$ nanotubes. J Mech Behav Biomed Mater. 2014; 32:192-197.

57. Nejatian T, Johnson A, Noort RV. Reinforcement of denture base resin. Adv Sci Technol. 2006;49:124-129.

58. Harini P, Mohamed K, Padmanabhan TV. Effect of Titanium dioxide nanoparticles on the flexural strength of polymethylmethacrylate: An in vitro study. Indian J Dent Res. 2014;25:459-463.

59. Ahmed MA, El-Shennawy M, Althomali YM, Omar AA. Effect of titanium dioxide nano particles incorporation on mechanical and physical properties on two different types of acrylic resin denture base. World $J$ Nano Sci Eng. 2016;6:111-1119.

60. Elshereksi NW, Ghazali MJ, Muchtar A, Azhari CH. Perspectives for Titanium-derived fillers usage on denture base composite construction: a review article. Adv Mat Sci Eng. 2014;1:1-14.

61. Alwan SA, Alameer SS. The effect of the addition of silanized Nano titania fillers on some physical and mechanical properties of heat cured acrylic denture base materials. J Bagh Coll Dent. 2015;27:86-91.

62. Shibata T, Hamada N, Kimoto K, et al. Antifungal effect of acrylic resin containing apatite-coated $\mathrm{TiO}_{2}$ photocatalyst. Dent Mater $J$. 2007;26:437-444

63. Sawada T, Sawada T, Kumasaka T, et al. Self-cleaning effects of acrylic resin containing fluoridated apatite-coated titanium dioxide. Gerodontology. 2014;31:68-75.

64. Elshereksi NW, Mohamed SH, Arifin A, Mohd Ishak ZA. Effect of filler incorporation on the fracture toughness properties of denture base polymethylmethacrylate. J Phys Sci. 2009;20:1-12.

65. Elshereksi NW, Mohamed SM, Arifin Z, Mohd Ishak ZA. Thermal characterization of poly (Methyl Methacrylate) filled with barium titanate as denture base material. J Phys Sci. 2014;25:15-27.

66. Casemiro LA, Gomes Martins CH, Pires-de-Souza Fde C, Panzeri H. Antimicrobial and mechanical properties of acrylic resins with incorporated silver-zinc zeolite - part I. Gerodontology. 2007;25: 187-194.

67. Suganya S, Ahila SC, Kumar BM, Kumar MV. Evaluation and comparison of anti-Candida effect of heat cure polymethylmethacrylate resin enforced with silver nanoparticles and conventional heat cure resins: An in vitro study. Indian J Dent Res. 2014;25:204-207.

68. Acosta-Torres LS, Mendieta I, Nuñez-Anita RE, Cajero-Juárez M, Castaño VM. Cytocompatible antifungal acrylic resin containing silver nanoparticles for dentures. Int J Nanomed. 2012;7:1-10.

69. Monteiro DR, Gorup LF, Takamiya AS, de Camargo ER, Filho AC, Barbosa DB. Silver distribution and release from an antimicrobial denture base resin containing silver colloidal nanoparticles. J Prosthodont. 2012;21:7-15

70. Li Z, Sun J, Lan J, Qingguo Q. Effect of a denture base acrylic resin containing silver nanoparticles on Candida albicans adhesion and biofilm formation. Gerodontology. 2014;28:1-8.

71. Oei JD, Zhao WW, Chu L, et al. Antimicrobial acrylic materials with in situ generated silver nanoparticles. J Biomed Mater Res. 2012;100: 409-415.

72. Wady AF, Machado AL, Zucolotto V, Zamperini CA, Berni E, Vergani CE. Evaluation of Candida albicans adhesion and biofilm formation on a denture base acrylic resin containing silver nanoparticles. J Appl Microbiol. 2012;112:1163-1172.

73. Azeez ZA, Fatah NA. The effect of incorporation of prepared Ag-Zn Zeolite on some properties of heat polymerized acrylic denture base materials. J Bagh Coll Dent. 2015;27:63-69.

74. Hamedi-Rad F, Ghaffari T, Rezaii F, Ramazani A. Effect of nanosilver on thermal and mechanical properties of acrylic base complete dentures. J Dent (Tehran). 2014;11:495-505. 
75. Ghafari T, Hamedi-Rad F, Ezzati B. Does addition of silver nanoparticles to denture base resin increase its thermal conductivity? J Dent Sch. 2014;32:139-144.

76. Ghaffari T, Hamedi-rad F, Ezzati B. In Vitro comparison of compressive and tensile strengths of acrylic resins reinforced by silver nanoparticles at $2 \%$ and $0.2 \%$ concentrations. J Dent Res Dent Clin Dent Prospect. 2014;8:204-209.

77. Nam KY, Lee CH, Lee CJ. Antifungal and physical characteristics of modified denture base acrylic incorporated with silver nanoparticles. Gerodontology. 2012;29:413-419.

78. Mahross HZ, Baroudi K. Effect of silver nanoparticles incorporation on viscoelastic properties of acrylic resin denture base material. Eur J Dent. 2015;9:207-212.

79. Morsy MA, Al-Daous MA. Mechanical properties evaluation of new AuNP-PMMA Composite. Int Rev Chem Eng. 2013;5:65-70.

80. Morsy MA, Al-Daous MA. Gold nanoparticles-PMMA composite for denture base: Synthesis, mechanical and thermal characteristics. $A K U$ J Sci Eng. 2014;14:369-374.

81. Nam KY. Characterization and bacterial anti-adherent effect on modified PMMA denture acrylic resin containing platinum nanoparticles. J Adv Prosthodont. 2014;6(3):207-214.

82. Aoyagi Y, Miyasaka T, Ando N. Application of noble metal cluster to PMMA resin and influence on mechanical properties and color. Dent Mater J. 2015;34(6):781-788.

83. Tham WL, Chow WS, Mohd Ishak ZA. Simulated body fluid and water absorption effects on poly (methyl methacrylate)/hydroxyapatite denture base composites. eXPRESS Polymer Lett. 2010;4:517-528.

84. Pan Y, Fengwei L, Xu D, Jiang X, Yu H, Zhu M. Novel acrylic resin denture base with enhanced mechanical properties by the incorporation of PMMA-modified hydroxyapatite. Prog Nat Sci Mat Int. 2013;23:89-93.

85. Alnamel HA, Mudhaffer M. The effect of Silicon dioxide Nano-Fillers reinforcement on some properties of heat-cure polymethylmethacrylate denture base material. J Bagh Coll Dent. 2014;26:32-36.

86. Balos S, Pilic B, Markovic D, Pavlicevic J, Luzanin O. Polymethylmethacrylate nanocomposites with low silica addition. J Prosthet Dent. 2014;111:327-334.

87. Da Silva LH, Feitosa SA, Valera MC, de Araujo MA, Tango RN. Effect of the addition of silanated silica on the mechanical properties of microwave heat-cured acrylic resin. Gerodontology. 2012;29:1019-1023.

88. Cevik P, Yildirim-Bicer AZ. The effect of silica and prepolymer nanoparticles on the mechanical properties of denture base acrylic resin. J Prosthodont. Epub 2016 Nov 29.

89. Maine FW, Shepherd PD. Mica reinforced plastics: a review. Composites. 1974;5:193-200.

90. Mansour MM, Wagner WC, Chu TM. Effect of mica reinforcement on the flexural strength and microhardness of polymethylmethacrylate denture resin. J Prosthodont. 2013;22:179-183.

91. Al-Bakri IA, Harty D, Al-Omari WM, Swain MV, Chrzanowski W, Ellakwa A. Surface characteristics and microbial adherence ability of modified polymethylmethacrylate by fluoridated glass fillers. Aust Dent J. 2014;59(4):482-489.

92. Miki S, Kitagawa H, Kitagawa R, Kiba W, Hayashi M, Imazato S. Antibacterial activity of resin composites containing surface pre-reacted glass-ionomer (S-PRG) filler. Dent Mater. 2016;32(9):1095-1102.

93. Tsutsumi C, Takakuda K, Wakabayashi N. Reduction of Candida biofilm adhesion by incorporation of prereacted glass ionomer filler in denture base resin. J Dent. 2016;44:37-43.

94. Ghaffari T, Barzegar A, Hamedi Rad F, Moslehifard E. Effect of nanoclay on thermal conductivity and flexural strength of polymethyl methacrylate acrylic resin. J Dent (Shiraz). 2016;17(2):121-127.

95. Abdallah RM. Evaluation of polymethyl methacrylate resin mechanical properties with incorporated halloysite nanotubes. J Adv Prosthodont. 2016;8:167-171.

96. Wang R, Kayacan R, Küçükeşmen C. Nanotubes/polymethyl methacrylate composite resins as denture base materials. In: Zhang M, Naik RR, Dai L, editors. Carbon Nanomaterials for Biomedical Applications. 1st ed. Berlin: Springer International Publishing; 2015:227-240.
97. Mahmood WS. The effect of incorporating carbon nanotubes on impact, transverse strength, hardness, and roughness to high impact denture base material. J Bagh Coll Dent. 2015;27:96-99.

98. Ibrahim RA. The effect of adding single walled carbon nanotube with different concentrations on mechanical properties of heat-cure acrylic denture base material. J Bagh Coll Dent. 2015;27:28-32.

99. Qasim SB, Al Kheraif A, Ramakrishaniah R. An investigation into the impact and flexural strength of light cure denture resin reinforced with carbon nanotubes. World Appl Sci J. 2012;18:808-812.

100. Wang R, Tao J, Yu B, Dai L. Characterization of multiwalled carbon nanotube-polymethyl-methacrylate composite resins as denture base materials. J Prosthet Dent. 2014;111:318-326.

101. Dolmatov VY, Voznyakovskii AP, Veretennikova MV. Modification of polymers using detonation-synthesized ultradispersed diamonds (nanodiamonds). J Superhard Mater. 2001;23:75-78.

102. Shenderova O, Tyler T, Cunningham G, et al. Nanodiamond and onionlike carbon polymer nanocomposites. Diamond Relat Mater. 2007; 16:1213-1217.

103. Protopapa P, Kontonasaki E, Bikiaris D, Paraskevopoulos KM, Koidis P. Reinforcement of a PMMA resin for fixed interim prostheses with Nanodiamonds. Dent Mater J. 2011;30:222-231.

104. Avazkonandeh-Gharavol MH, Sajjadi SA, Zebarjad SM, et al. Effect of heat treatment of nanodiamonds on the scratch behavior of polyacrylic/ nanodiamond nanocomposite clear coats. Prog Organ Coat. 2013; 76:1258-1264.

105. Dolmatov VY. Polymer-diamond composites based on detonation nanodiamonds. Part 2. J Superhard Mater. 2007;29:65-75.

106. Vallittu PK, Narva K. Impact strength of a modified continuous glass fiber polymethylmethacrylate. Int J Prosthodont. 1997;10: 142-148.

107. Safarabadia M, Khansarib NM, Rezaeic A. An experimental investigation of $\mathrm{HA} / \mathrm{AL}_{2} \mathrm{O}_{3}$ nanoparticles on mechanical properties of restoration materials. Eng Solid Mech. 2014;2:173-182.

108. Han Z, Zhu B, Chen R, Huang Z, Zhu C, Zhang X. Effect of silversupported materials on the mechanical and antibacterial properties of reinforced acrylic resin composites. Mat Design. 2015;65: 1245-1252.

109. Aljafery MA, Basima MA. Effect of addition $\mathrm{ZrO}_{2}-\mathrm{Al}_{2} \mathrm{O}_{3}$ nanoparticles mixture on some properties and denture base adaptation of heat cured acrylic resin denture base material. J Bagh Coll Dent. 2015;27: 15-21.

110. Alhareb AO, Akil HM, Ahmad ZA. Mechanical Properties of PMMA Denture Base Reinforced by Nitrile Rubber Particles with A12O3/YSZ Fillers. Procedia Manufact. 2015;2:301-306.

111. Alhareb AO, Akil HM, Ahmad ZA. Influence of A12O3/Y-TSZ mixture as filler loading on the radiopacity of PMMA denture base composites. Procedia Chem. 2016;19:646-650.

112. Chen S, Liang W. Effects of fillers on fiber reinforced acrylic denture base resins. Mid Taiwan J Med. 2004;9:203-210.

113. Muklif OR, Ismail IJ. Studying the effect of addition a composite of silanized Nano- $\mathrm{Al}_{2} \mathrm{O}_{3}$ and plasma treated polypropylene fibers on some physical and mechanical properties of heat cured PMMA denture base material. J Bagh Coll Dent. 2015;27:22-27.

114. Alhareb $\mathrm{AO}$, Ahmad ZA. Effect of $\mathrm{Al}_{2} \mathrm{O}_{3} / \mathrm{ZrO}_{2}$ reinforcement on the mechanical properties of PMMA denture base. J Reinf Plast Compos. 2011;30:1-8.

115. Zhang XY, Zhang XJ, Huang ZL, Zhu BS, Chen RR. Hybrid effects of zirconia nanoparticles with aluminum borate whiskers on mechanical properties of denture base resin PMMA. Dent Mater J. 2014;33: 141-146.

116. Salman TA, Khalaf HA. The influence of adding of modified $\mathrm{ZrO}_{2}$ $\mathrm{TiO}_{2}$ nanoparticles on certain physical and mechanical properties of heat polymerized acrylic resin. J Bagh Coll Dent. 2015;27:33-39. 


\section{Publish your work in this journal}

The International Journal of Nanomedicine is an international, peerreviewed journal focusing on the application of nanotechnology in diagnostics, therapeutics, and drug delivery systems throughout the biomedical field. This journal is indexed on PubMed Central, MedLine, CAS, SciSearch $\AA$, Current Contents $\AA /$ Clinical Medicine,
Journal Citation Reports/Science Edition, EMBase, Scopus and the Elsevier Bibliographic databases. The manuscript management system is completely online and includes a very quick and fair peer-review system, which is all easy to use. Visit http://www.dovepress.com/ testimonials.php to read real quotes from published authors.

Submit your manuscript here: http://www.dovepress.com/international-journal-of-nanomedicine-journal 